\title{
Designing an ergonomics backpack for student aged 7-9 with user centred design approach
}

\author{
Mahdie Amiri ${ }^{\mathrm{a},}{ }^{*}$, Mohsen Safar Dezfooli ${ }^{\mathrm{b}}$, Seyed Reza Mortezaei ${ }^{\mathrm{b}}$ \\ ${ }^{a}$ School of Architecture and Urban Design, Department of Industrial Design, Iran University of Science \& \\ Technology (IUST), 16846-13114, IUST,University street, Narmak, Tehran, Iran \\ ${ }^{\mathrm{b}}$ School of Architecture and Urban Design, Department of Industrial Design, Iran University of Science \& \\ Technology (IUST), Faculty of Industrial Design
}

\begin{abstract}
Researches explored that backpacks are the most common means of carrying school supplies for students. Carrying heavy backpacks causes a wide range of disorders such as musculoskeletal disorders and postural malfunction. User Centered Design has proven its suitability to produce high efficient products with themost adaptability toconsumer demands. This approach combined with consideration of normal standards and ergonomics features, with the recognition of children's needs and requirements, has been used in this research to prepare an initial design of a backpack. After that, its prototype was manufactured. The backpack was tested by 120 elementary students in three stepsof form, ergonomics and load sense. A redesign was performed that has applied the results of the test run. Results showed that this new backpack can considerably reduce the effective loads on the shoulders, back and neck.
\end{abstract}

Keywords: Backpack, User Centred Design, Students of elementary school, Ergonomics

*Corresponding author: E-mail: m_amiri@arch.iust.ac.ir 


\section{Introduction}

It has been seen that more than 80 percent of elementary school students in Iran use backpacks to carry their books and school supplies [1]. Research explored that the backpacks are the most suitable tool forcarrying daily school equipment since they can distribute the load symmetrically [2]. Carrying heavy backpacks could cause a wide spectrum of pain related to musculoskeletal disorders and postural dysfunctions [3]. Whittfield found that the pressure caused by carrying heavy backpacks is one of the most important factors in bone muscle pain [4].

School age children are susceptible to musculoskeletal, so using non-ergonomic backpack will result in serious physical injuries. The results of Makcie et al., investigation on four different school backpack showed that backpack weight has the greatest impact on stress and pressure on shoulder [5]. Bahrian [1] also found that a heavy backpack creates distance between the vertebra, spinal curvature, nervous pains, neck pains and make postural abnormalities [1].

Weight is a controversial issue while designing backpacks which is discussed and argued upon by many researchers. Some research focusing on the amount of weight that should be carried by an individual in a backpack, suggest a weight that is $10 \%$ to $15 \%$ of the body weight $[6,7,8]$. Mackenzie et al.,[9] believe that backpack weight more than 15 to 20 percent of a childs body weight is relevant to back pain [9]. Alwiah et al.[10] understood that carrying heavy backpack with a load weighing from $15-20 \%$ of the body weight will result in an increased deviation angle of the upper body [10]. This case has been evaluated in other reports $[3,7,8]$. However some researchers believe that even carrying $\% 10$ of the body weight may cause some injuries [3, 11]. Some Studies evaluating the effect of carrying heavy backpacks on cardio-respiratory changes on Iranian high school students recommend that the load in the backpack should weigh between $7.5-8 \%$ of the body weight $[12,13,14]$, And a study on Saudi Arabian students advises $5 \%$ of the body weight[11]. Ramprasad and collegues believe that even carrying $5 \%$ of the body weight can dramatically change the angle of upper and lower body[3].

In Iran the statistics show that $57 \%$ of the students carry backpacks weighed more than $10 \%$ of their body weight[15]. The results show that $24 / 6 \%$ of students use only one shoulder strap backpacks[16].
It has been revealed that the form of backpacks could be leaded to better weight distribution and comfort [17]. Mackenzie and colleagues reviewed recent literature and reported general findings with recommendations for better designed packs that fit properly, reducing weight carried and using safe lifting techniques to reduce backpack complaints [9]. Thus designing an ergonomics backback that could help balance weight and reduce the damages caused by an unsuitable backpack is critical. The User Centered Design (UCD) approach could be the most effective method in designing backpacks in which all ergonomic criteria can be met and the demands, requirements and preferences of students can be satisfied. UCD is an approach to designing useful and ease of use into products and systems, thereby creating a total customer experience. It is a design philosophy in which the emphasis is on the user and the aim is a high level of usability[18]. The roots of this approach has started in Norman and Draper studies [19, 20]. Norman emphasized on discovering the full demands of users and the targets of application[21]. In this method, the user profoundly influences the designed product and as a cooperator accompanies the designer throughout the process. It is done by aquiring techniques, procedures and methods that entirely focuses on the user in a life cycle [22].

The first phase of the UCD is to understand the users, their tasks, their occupation, and their needs [22, 18]. In a circular process, first with the users' assistance basic needs, aesthetics and desired functions should be recognized [23]; secondly, the product should be designed and drafted and a prototype should be manufactured; and finally it should be evaluated by the user[18]. In the developing stage, the product isdesigned based on the features of the user. In returnthe users will evaluate and help optimize the product.[23]. Thisis done by usability test. The usability test makes it possible for user to find errors in actual interaction withthe product [22]. Five main ingredient in user centered design showed in Figure

(1) based on ISO 13407 [24].

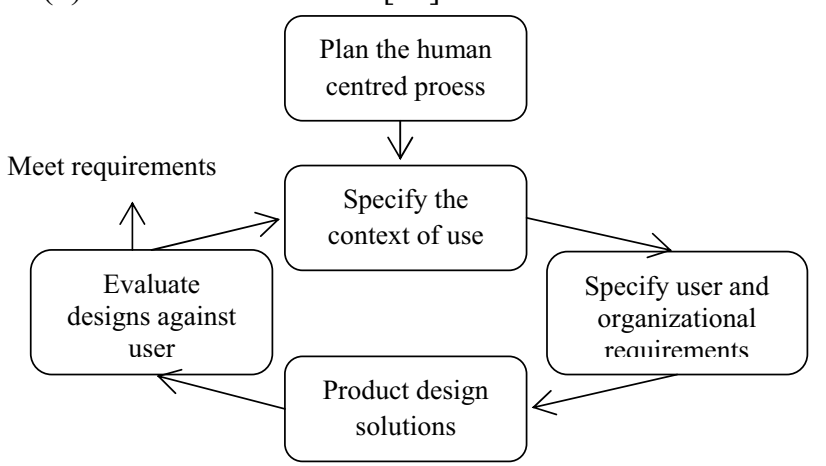

Figure 1 User Centred Design Cycle from ISO 13407[25] 
The aim of this research is to design a proper backpack for students 7-9 years old that decreases the effective load on their shoulders, neck and waist. Due to the fact that the backpacks were designed using UCD it is expected that the designed backpack inaddition to decreasing the effective load, would be aesthetically acceptable for students.

\section{Method}

120 seven to nine year old students, both boys and girls, from five elementary schools, participated in this process.
The needs and problems of students with their backpacks were identified by using UCD. Then the initial design was performed and its prototype was manufactured. The functional and ergonomic tests were done to measure the usability of new backpack. The backpack was redesigned implementing the students evaluations. In the end, the final design was surveyed by students. Methods used in each step of UCD are shown in Table (1). The methods were derived from Miguire proposed techniques [26].

Table 1

Methods of user centered design process based on Maguire's proposal [26]

\begin{tabular}{|c|c|c|c|}
\hline Context of use & Requirements & Design & Evaluation \\
\hline $\begin{array}{l}\text { - Identify stakeholders } \\
\text { - Context of use } \\
\text { analysis } \\
\text { - Field study/user } \\
\text { observation } \\
\text { - Ethnography } \\
\text { - Task analysis } 1 \\
\text { - Diary keeping } \\
\text { - Hid video recording }\end{array}$ & $\begin{array}{l}\text { - Stakeholder analysis } \\
\text { - User requirements } \\
\text { Interview } \\
\text { - Focus groups } \\
\text { - Standard } \\
\text { - Identifying the true } \\
\text { and false behavior of } \\
\text { user } \\
\text { - Secret filming in the } \\
\text { way of school and } \\
\text { home } \\
\text { - Think Aloud }\end{array}$ & $\begin{array}{l}\text { - Brainstorming } \\
\text { - Software prototyping }\end{array}$ & $\begin{array}{l}\text { - Participatory } \\
\text { Evaluation } \\
\text { - Satisfaction } \\
\text { Questionnaires } \\
\text { - Assessing cognitive } \\
\text { Workload } \\
\text { - Post-experience } \\
\text { Interviews } \\
\text { - Hidden } \\
\text { recording video } \\
\text { - Think Aloud } \\
\text { - Standard } \\
\text { - Prototype }\end{array}$ \\
\hline
\end{tabular}

As shown in table 1 the students kept a dairy recording their experience. Examining 15 of the dairies, revealed that the most interaction between students and their backpacks happens during school hours (Figure 2).

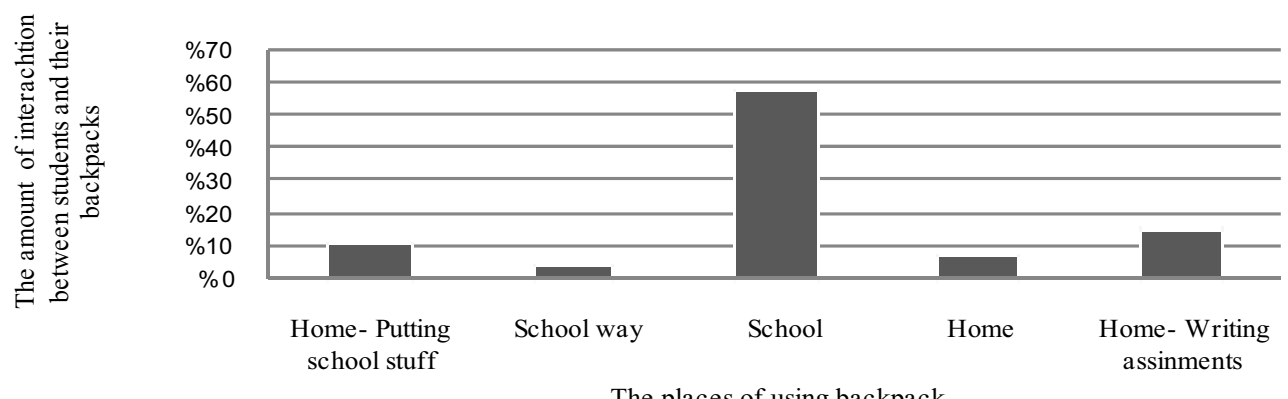

Figure 2 The amount of student interaction with backpack in different places based on dairy keeping approach 
According to user's requirements, preferences and wishes, and with consideration of ergonomics featurs and standards, with brainstorming among designers the initial was drafted. Figure (3) shows the initial designed backpack. Based onanthropometric principles, even for a nine year old students with the 5th percentile, the backpack will be located at the top of hip.
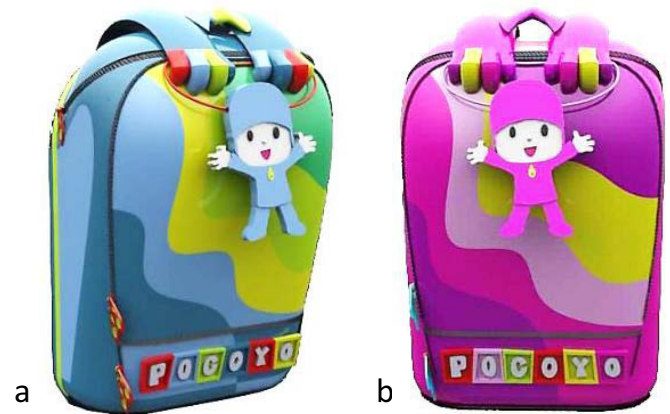

Figure 3 Initial design of a backpack with desirable color for: a) boys and b) girls

A double strap backpack is associated with less discomfort at the back of the neck, less perceived pressure on the shoulders and a lower rating of perceived exertion [27], it is also associated with less restrictive type of ventilatory impairment in lung function than a similarly weighted single strap backpack harness [28]. Thus the designed backpack is a double strap wide well-padded, with hip belts and shoulder straps. As mentioned before, the overweight of backpacks is the most important factor in creating physical injuries in students. In this study two solutions were presented to decrease the weight felt on the shoulders and back. These include: changing the connecting position of the straps from behind to the front of the bag (Figure 4) and classifying the inner side of backpack for better organization (Figure 5).

Changing the position of straps would lead to increasing the contribution of vertical loading on the shoulder. On the other hand, the conection area would be increased, therefore the pressure felt by students would decrease. The center gravity of the backpack would be trasfered to the upper section by the new organizing system. In this condition, the distance between the $\mathrm{CG}$ of backpack and the shoulder would be decreased and the shoulder would bear less torque.

There is a foam seat attached to the back of the backpack (Figure 6). This is to add comfort for students while sitting on a chiar or bench during school hours. Figure 5 shows the prototype of initial designed backpack.
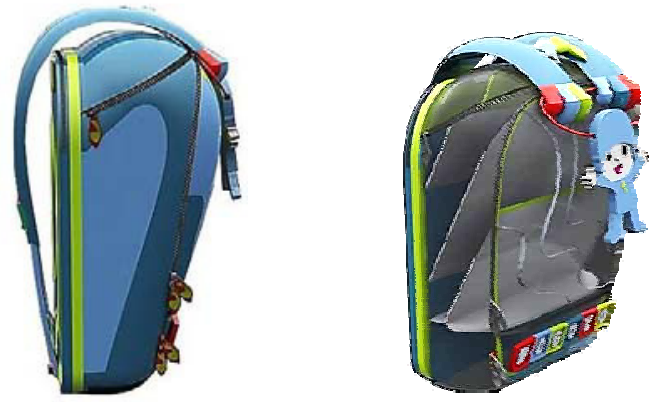

Figure 4 Changing straps position Figure 5 Inner side classification

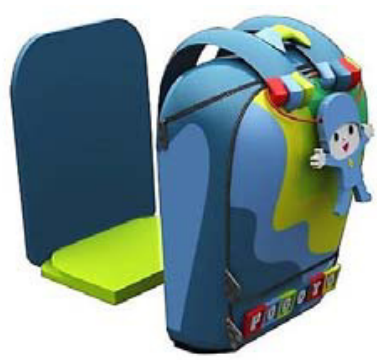

Figure 6 Seat with foam material

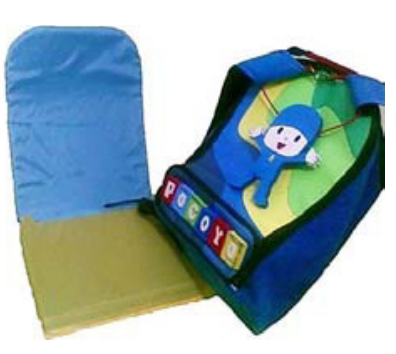

Figure 4 Prototype of initial designed backpack

\section{Evaluation process}

The three main domains of backpack design are ergonomics, form and graphics. The Backpack prototype was assessed by students to ergonomics and form. The color of backpack was selected according to 7-9 year old Iranian children preferences, marketing evaluation and parents ideas.

Post-experience interviews, assessing cognitive workload and think aloud were methods used in this stage. In Post-experience interview method, 3 male and 3 female students aged 7-9 years old were selected. They were asked to use the prototype of backpack for 2 days. After this time, students were interviewed.

To evaluate the workload, 15 students were required to walk 400 meters in a determined path with their own backpacks, then put their daily equipments in the new backpack and repeat this procedure one more 
time. They were asked to compare the ease of use and the sense of work load between their own backpack and the new backpack. They also talked about their experience of carrying the new backpack with the new shoulder straps.

In the final method of ergonomics evaluation, the new backpack was put in possession of 15 students for 15 minutes. Later they were asked to vocalize their opinions and thoughts regarding the backpack.

The methods used in the form evaluation stage were visual methods, functional assessment, think aloud and post-experience interviews. In the visual method, a prototype of backpack was just shown to 120 students in diverse classroom (on average each class had 15 students), and they were asked to comment and express their ideas in this regard. For functional evaluation, 15 students were asked to bring out their equipment from their own backpacks and to put them in the new classified backpack. In the relocation process, they were asked to vocalize their thoughts, feelings, and opinions. After accommodating their school supplies in the new backpack, they were interviewed to find their sense of satisfaction.

\section{Results}

The results of the post-experience interview for ergonomics evaluation are shown in Figure 8.
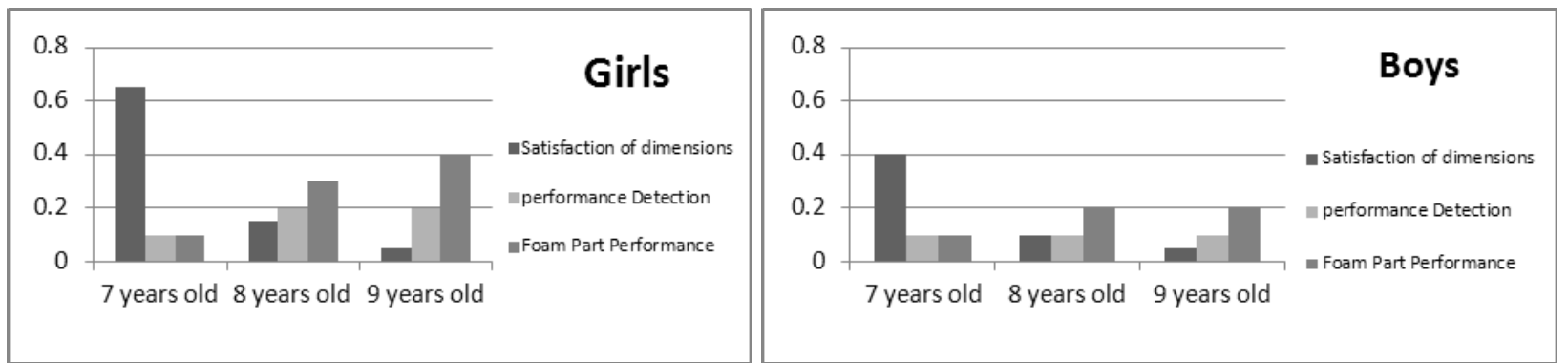

Figure 5 The amount of satisfaction of dimension and performance detection due to gender and age separation

Figure 8 explores that the saticfaction of the dimention is in acceptable level only in 7 year old girl students and The rate of the performance detection of the backpack was very low. Further more the detection of the foam part performance was significantly different in 9 year old girl students in compared to others. The small dimension of the backpack was the first problem that all students mentioned. The equipments arrangement was a time consuming procedure. To use the new straps of the backpack was hard durring first day but could be done alone the next day.

In the assessment of the sensing load, all students described that the new backpack was lighter than their own. Nine students felt better with the conventional straps while six preferred the new straps. four students expressed discomfort because the new straps caused the backpack not to touch their back.

During th workload evaluation in which the backpack was given to student for 15 minutes; the students were filmed simultaneously. At first, they thought that the backpack was too small and believed that there was not enough capacity for their stuff. The upper section zip was opened and students were not curious about the other parts of the backpack. They tried to put all their stuffs into the upper section of the backpack while they did not pay attention to other sections while insisting about the lack of space. 12 out of 15 students could not answer the question about the application of different parts of backpack. 11 out of 15 students were not satisfied with the new classifying system while the rest of students welcomed it. 86 percent of students were not able to guess the application of the foam seat, and yet when they were notified about its work, they described to be essential.

By evaluating the form all the students enthusiastically described it beautiful and different. The Product dimensions were questionable for students between 8 and 9 years old. Students were asked about different parts of the backpack and most of them did not understand the application of these sections. The foam seat was shown to students but they did not recognize what it was or what its application was. 


\section{Redesign}

Based on the results of the evaluations, changes were conducted in the initial backpack and the final backpack was designed (Figure 9) and named the UCD backpack.

The Results of the functional evaluation showed that the girls' satisfaction of backpack dimension were more than boys. This result for 7 years old girls was significantly different with 8 and 9 years old girls (Figure 8). So with keeping ergonomics features, the dimension of backpack became larger in redesign concept. Results also revealed the low rate of recognition of the backpack's performance in both girls and boys(Figure 8). So, the backpack must be more simple for use. According to the behavior of students, the inner shelves were eliminated due to complexity and the largest part of new backpack was placed near the back with a zipper on top side.

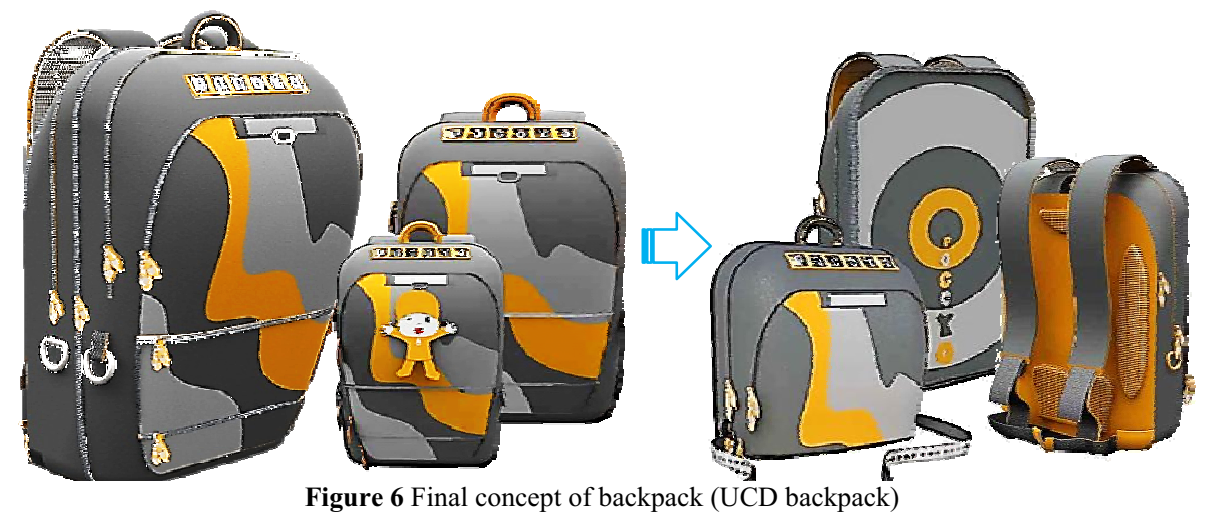

The distribution of the backpack load according to ergonomics features is shown in Figure 10. In the UCD backpack, the largest part is near the back, so students have to put the heaviest books in this part. The second large part is placed upper and separated from other parts. This section is designed to fit notebooks. It is the semi heavy part. The lower parts are designed to put snacks and stationery that are very light. Figure 11 is shown the distributed load in new backpack.

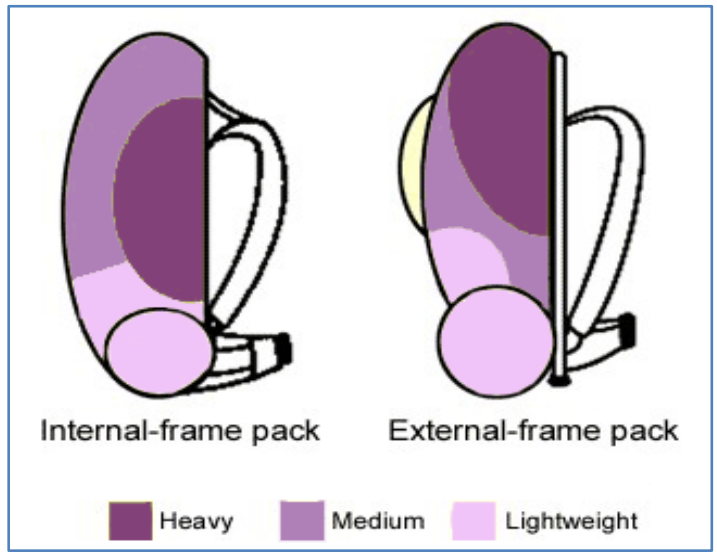

Figure 8 The distribution of the backpack load according to ergonomics features

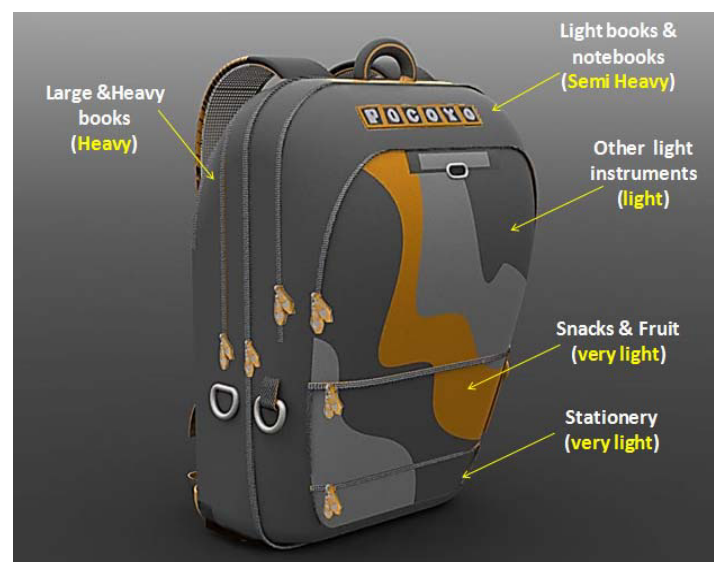

Figure 7 Load Distributing in UCD backpack 
Although Backpack weight of $10-15 \%$ has been recommended as an acceptable limit for schoolchildren there is still no clear guideline regarding where the backpack centre gravity (CG) should be positioned Chow believes that carried backpack with a centre gravity positioned at T12 induces relatively less effect on spinal deformation and repositioning error in schoolchildren [7]. Legg concluded that the metabolic and biomechanical strain of load carriage can be minimized by bringing the centre of gravity of the load as near to the centre of gravity of the carriers' body as possible [29]. Division parts in the UCD backpack, distributes the loads better and in addition, it aligns the backpack's

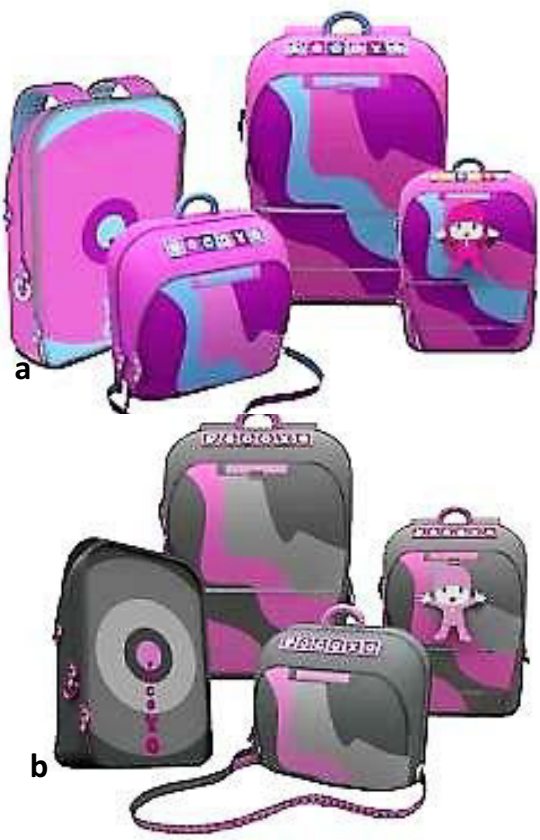

Figure 9 Color scheme in final school backpack design for elementary students

a. For girls in first level b. For girls in second and third level c. For boys in first level d. For boys in second and third level

According to the children's requirement, the various parts of the UCD backpack were designed detachable (Figure 13). The back part can be used alone in days when student's school supplies are light. The front center gravity with the body's center gravity. These are important factors in reducing the effective load on shoulders, waist and neck.

Results also showed that children have problems finding the shoulders straps in regards to wearing the backpack. So shoulders straps connections were shifted to the top of the backpack inbetween the heavy and semi-heavy section.

In accordance with the results of student preferences of colors, there were differences in the preferences of the various ages. So it is wrong to use a unique color scheme for this backpack (7-9 years old). The UCD backpack is presented in variety of colors scheme in Figure 12.

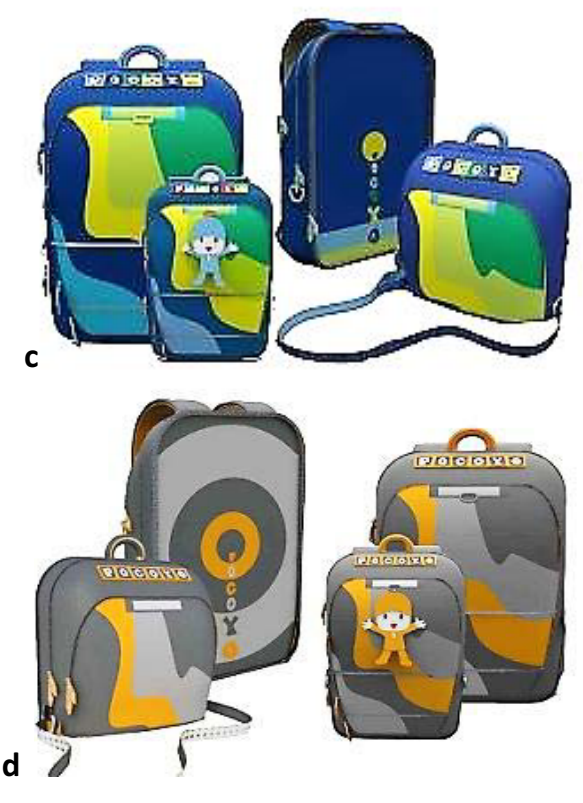

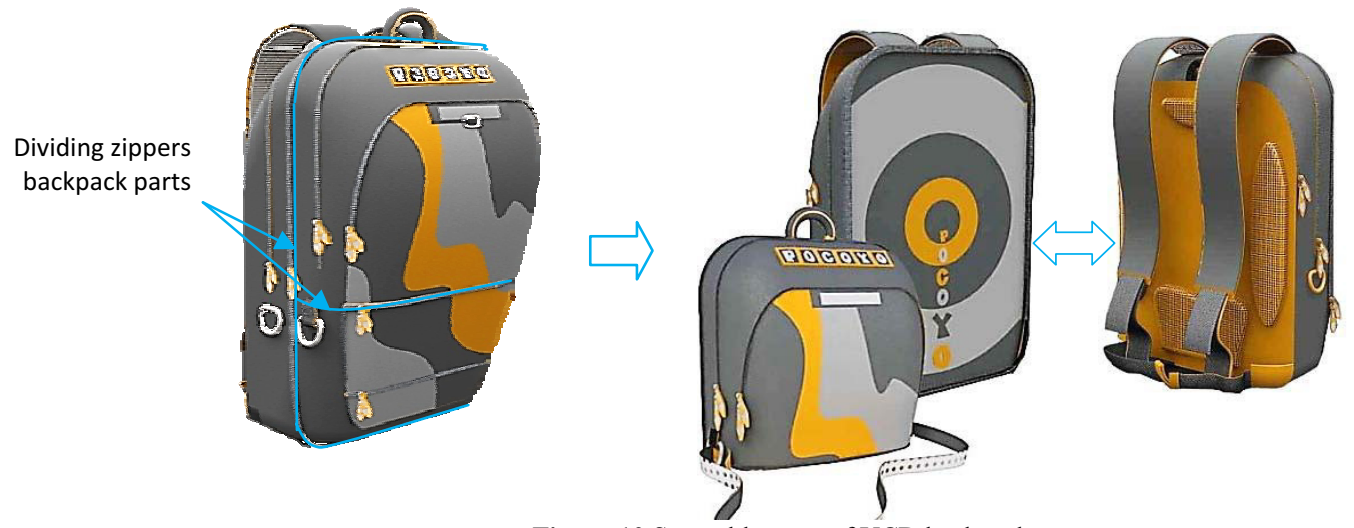

Figure 10 Separable parts of UCD backpack

part with conducting a shoulder strap can be used for outings and picnics. These parts are connected together with throughout zipper. 


\section{Final design evaluation}

15 students visually evaluated the UCD backpack. First they were required to score the backpack's form, graphic and size with rating it with numbers from 1 to 10 . Also, they were asked to guess the performance of each part of the backpack. The aim of this evaluation was to measure the rate of user's satisfaction of the UCD backpack.

Figure 14 shows the result of the interview on UCD backpack in comparision with initial designed backpack.

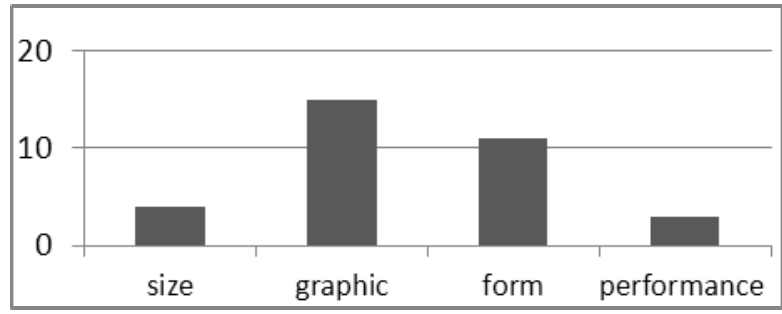

a

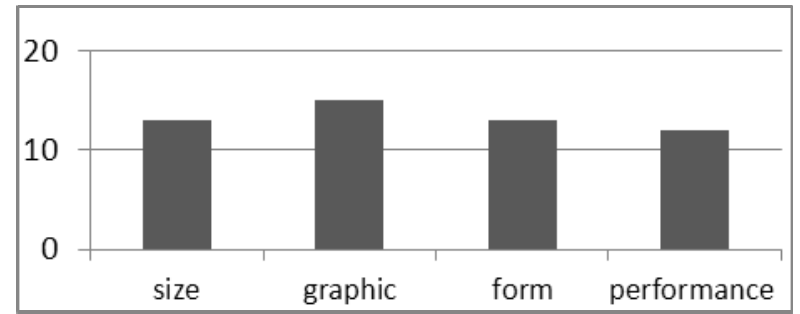

b

Figure 11 Rate of student satisfaction of a. initial backpack b. UCD backpack

One probable concerning the UCD backpack users may be the strength of zipper that connects the back and front parts. In the most critical conditions, the maximum load on this connection will be $4 \mathrm{~kg}$. To measure the strength of zipper, a fixture was designed (Figure15). The actual loading was simulated with a tension test. The result (Figure16), explored that in the static loading, the zipper connection failed at 267 kilograms which is nearly 66 times of the real force. Considering this confidence level in static loading, it could be interfered that zipper resistance in dynamic loading will be guaranteed .

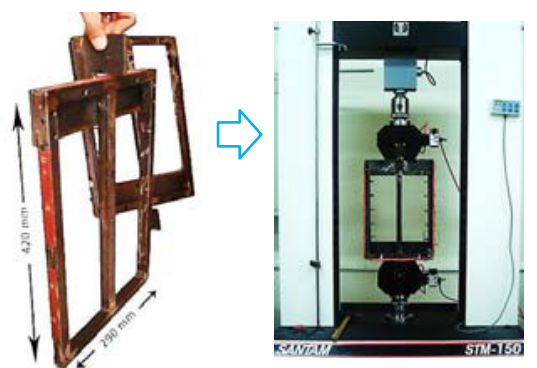

Figure 12 Simulated fixture of zipper connection

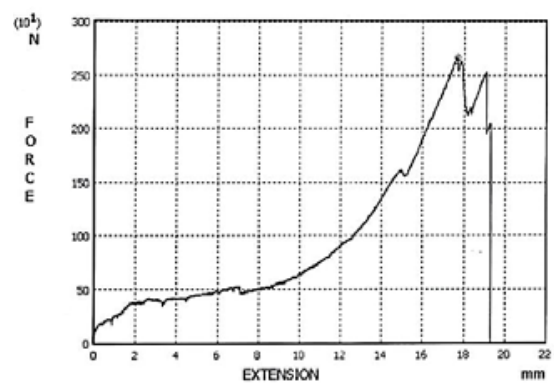

Figure 13 Force-displacement graph of connection zipper

\section{Conclusion}

In spite of the fact that there are huge amounts of investigation in the field of ergonomic features of backpacks, there are few research focused on the design of backpacks based on ergonomic requirements. In this research it was tried that ergonomic features was practically used in the design of backpack. Although the ergonomic criteria were applied to the initial design, there were some problem such as unsuitable dimensions, uncomfortable condition of usage and misunderstanding of the application of different parts of backpack, so the initial ergonomic backpack was not welcomed considerably. One of the reasons can be the fact that the backpack was designed for the age range of 7 to 9 year old students, thus the appearance and attraction were the important influential factors in the design. The initial backpack was modified based on the user centered design approach and the second round of test revealed that user preference has been correctly applied to the second design. in conclusion, it could be understood from the this research that designing ergonomic backpack for children along with user centered design not only solves the ergonomic issues of current backpacks, but also involves the children in the design procedure. So there can be a proper correlation between the ergonomic stand of the design and other features like appearance and aesthetics. 


\section{References:}

[1] Behrian, Maryam, Non-standard backpack, Dastavard Journal, 28 (2008): 32-39

[2] Hong Y., Lau T. C. and Li J. X., Effects of loads and carrying methods of school bags on movement kinetics of children during stair walking, Research in Sports Medicine 11 (2003): 33-49.

[3] Ramprasad M., Alias J. and Raghuveer A.K., Effect of Backpack Weight on Postural Angles in Preadolescent Children, Indian Pediatrics; 47 (2010): 575-580

[4] Whittfield J., Legg S.J., Hedderley D.I., Schoolbag Weight and Musculoskeletal Symptoms in New Zealand Secondary Schools, Applied Ergonomics 36 (2005): 193-198

[5] Mackie H. W., Stevenson J. M., Reid S. A., Legg S. J., The effect of simulated school load carriage configurations on shoulder strap tension forces and shoulder interface pressure, Applied Ergonomics 36 (2005): 199-206

[6] Brackley HM., Stevenson JM., Are children's backpack weight limits enough? A critical review of the relevant literature, Spine 29(19), 2004: 2184-2190

[7] Chow D.H.K., Ou Z.Y., Wang X.G. and Lai A., Shortterm effects of backpack load placement on spine deformation and repositioning error in schoolchildren, Ergonomics; 53 No. 1 (2010): 56-64

[8] Hong Youlian, Li Jing-Xian, Tik-Pui Fong Daniel, Effect of prolonged walking with backpack loads on trunk muscle activity and fatigue in children, Journal of Electromyography and Kinesiology 18 (2008): 990-996

[9] Mackenzie W.G., Sampath J.S., Kruse R.W. and SheirNess G.J., Backpacks in children. Clinical Orthopaedics 409 (2003): 78 - 84 .

[10] Alwiah Sh., Rahman Syed Abd., Rambely A. Sh., Ahmad R. R., A Preliminary Studies on the Effects of Varying Backpack Loads on Trunk Inclination During Level Walking, European Journal of Scientific Research; 28 No. 2 (2009): 294-300

[11] Hazzaa M. Al-Hazzaa, School Backpack; How much load do Saudi school boy carry on their shoulders, Saudi Med J; 27 (10), 2006: 1567-1571

[12] Hosseini, H., Daneshmandi,H., Rahmani nia, F., Study of heart rate response, Oxygen consumption (VO2) and energy expenditure of students while carrying school backpacks, Journal of Research in Sports Sciences;22, Spring 2009: 63-80

[13] Daneshmandi H., Rahmani-Nia F. and Hosseini S. H., Effect of carrying school backpacks on cardiorespiratory changes in adolescent students, Sport Sciences for Health; 4 (2008): 7-14

[14] Namazi zade, M., Ebrahim, KH., Sarreshte, M., Salehi, H., Kinematic effects of carrying backpack on walking and postural status in adolescents, Journal of motion; 16 , Summer 2003:5-11

[15] Tarhani, Fariba, Backpack Standard Evaluation of Elementary Students of Khoramabad, Yafte 39, Spring 2009: 6-13

[16] Zanganeh, M., Warning Alarm of Muskuleskeleta Desiease in Girls Students, Dastavard, Vol 22 (2006): 619

[17] Cottalorda J, Bourelle S, Gautheron V, Kohler R., Backpack and spinal disease: myth or reality?, Rev Chir Orthop Reparatrice Appar Mot.90(3), May 2004: 207. 14.
[18] Andrea F. Kravetz Esq., The Role of User Centered Process in Understanding Your User, Elsevier, (?)

[19] Vredenburg Karel, Mao Ji-Ye, Smith Paul W, Carey Tom, A Survey of User-Centered Design Practice, CHI; 4 No 1 (2002): 472-478

[20] Norman D. A. and Draper S.W., User-Centered System Design: New Perspectives on Human-Computer Interaction. Erlbaum, Hillsdale, NJ, 1986.

[21] Abras C., Maloney-Krichmar D., Preece J., UserCentered Design, In Bainbridge,W.Encyclopedia of Human Computer Intraction, Thousand Oaks: Sage Publication (in press), 2004

[22] Courage, Catherine and Baxter, Kathy, Understanding Your Users, A Practical Guide to User Requirements Methods, Tools, and Techniques, Morgan Kaufmann. ISBN: 1-55860-935-0, 2005.

[23] Namayandegi, Mohammad Hossein, Process of the User Center Design, Dastavard, Vol 26 (2008): 72-83

[24] ISO 13407: Human-centred Design Processes for Interactive Systems. Geneva: International Standards Organization. Also available from the British Standards Institute, London, 1999.

[25] Bevan, Nigel, Usability Net Methods for User Centered Design, Human Computer Interaction: Theory and Practice (part1), volume 1 (2003): 434-438

[26] Maguire, Martin, Methods to support human-centered design, Human-Computer Studies; 55 (2001): 587-634

[27] Legg Stephen, Cruz Christian, Chaikumarn Montakarn and Kumar Rupesh, Efficacy of subjective perceptual methods in comparing between single and double strap student backpacks, Third international cyberspace conference on ergonomics, 2002.

[28] Legg S. J., Cruz C. O., Effect of single and double strap backpacks on lung function, ERGONOMICS; 47 NO 3 (2004): $318-323$

[29] Legg S. J., Perko L., Campbell P., Subjective perceptual methods for comparing backpacks, ERGONOMICS; 40 NO 8 (1997): $809-817$ 